\title{
Lung function abnormalities in repaired oesophageal atresia and tracheo-oesophageal fistula
}

\author{
P Chetcuti, P D Phelan, R Greenwood
}

\begin{abstract}
Background Respiratory complications are common after neonatal repair of oesophageal atresia and tracheo-oesophageal fistula. The prevalence of lung function abnormalities and the relation between gastrointestinal complications and lung function has not been studied in a large number of patients.

Methods Lung volumes and flowvolume loops were measured in 155 patients without spinal curvature aged 6-37 years who had undergone surgery for oesophageal atresia and tracheooesophageal fistula.

Results Sixty four of the 155 patients had evidence of mild lower airways disease, with values for $F E V_{1}$ more than two standardised scores below the predicted value in $39(25 \%)$ and above 2 standardised scores for the residual volume (RV)/ total lung capacity (TLC) ratio in 64 (41\%). Restrictive lung disease (TLC more than 2 standardised scores below predicted) was present in $28(18 \%)$. Severe lung function abnormalities were present in under $10 \%$ of the 155 . Half the subjects had some evidence of extrathoracic tracheal obstruction, with a high ratio of expiratory to inspiratory flow for peak flow in $76(50 \%)$ and at $50 \%$ of vital capacity in $59(38 \%)$. Patients with radiological gastro-oesophageal reflux in early childhood had more airways obstruction and smaller lung volumes. Patients with current gastrointestinal symptoms were similar in their lung function to symptom free patients. Conclusions Minor lung function abnormalities are common in patients after repair of oesophageal atresia. Early diagnosis and management of gastrooesophageal reflux may help to minimise these lung function abnormalities.
\end{abstract}

(Thorax 1992;47:1030-1034)

Respiratory complications are common after repair of oesophageal atresia and fistula and tend to occur in the early postoperative years. ${ }^{12}$ Many factors may contribute to these problems, including recurrent inhalation of gastric or oesophageal contents, ${ }^{3}$ structural instability of the major airways, ${ }^{45}$ and abnormal airway epithelium. ${ }^{6}$

These repeated insults to the respiratory tract could be expected to lead to substantial abnormalities of lung function. Previous studies have been carried out on small numbers of patients ${ }^{7-10}$ and, in at least one, subjects were selected specifically because they were troubled by respiratory disorders. ${ }^{10}$ It seemed important therefore to study a broad group of patients to determine the prevalence of abnormalities of respiratory function, and where these were present to relate them to any gastrointestinal complications. Documentation of abnormal lung function may have implications for the management of various complications of oesophageal atresia and may indicate the need for long term surveillance of patients with abnormal function because of the risk of the development of progressive airways disease in adult life, particularly if additional respiratory insults come from the smoking of cigarettes.

\section{Methods}

PATIENTS

Five hundred and thirty eight patients with oesophageal atresia and tracheo-oesophageal fistula were managed at the Royal Children's Hospital, Melbourne, since the first successful repair in 1948 to the end of 1985 . Three hundred and sixty six survived, of whom 302 were reviewed as part of a long term follow up study. All case notes were studied for details of postoperative complications and subsequent hospital admissions. Radiological diagnoses of anastomotic stricture and gastro-oesophageal reflux were documented. Details of past medical history and current health were obtained from the patients and where possible the parents. Current respiratory problems were defined as episodes of wheezing, bronchitis (cough and constitutional disturbance lasting more than five days), or pneumonia in the 12 months before review. Current gastrointestinal symptoms were defined as dysphagia, heartburn, or regurgitation in the 12 months before review.

LUNG FUNCTION STUDIES

Lung function studies were performed in 203 of the 231 subjects over the age of 6 years. Studies were not possible in 25 because of poor cooperation or mental retardation, and three women were pregnant. Forty eight patients found to have spinal deformity by clinical examination were excluded from the analysis as this factor could make interpretation of results difficult. Their lung function is considered elsewhere. " Total lung capacity (TLC), vital capacity (VC), residual volume (RV), forced expiratory volume in one second $\left.(\mathrm{FEV})_{1}\right)$, mean forced expiratory volume at $25-75 \%$ of vital capacity $\left(\mathrm{FEF}_{25-75}\right)$, and inspiratory and 


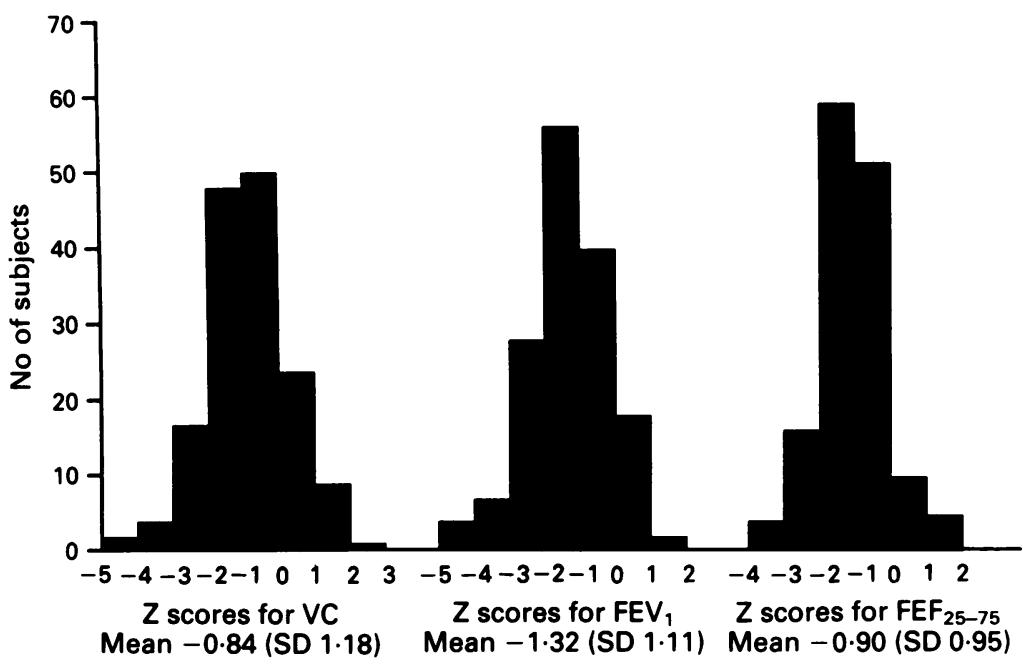

Figure 1 Distribution of vital capacity (VC), forced expiratory volume in one second $\left(F E V_{1}\right)$, and forced expiratory volume at $25-75 \%$ of vital capacity ( $F E F_{25-75}$ ) expressed as standardised scores ( $Z$ scores), with the mean and 1 standard deviation of the standardised scores.

expiratory flow-volume loops were measured in a pressure compensated integrated flow body plethysmograph (Jaegar Bodyscreen 2). The subjects were trained to perform maximally and the best of a minimum of three efforts in the seated position were recorded. $\mathrm{FEV}_{1} / \mathrm{VC}$, RV/TLC, peak expiratory to peak inspiratory flow (PEF/PIF), and mid expiratory to mid inspiratory flow $\left(\dot{\mathrm{VE}}_{50} / \dot{\mathrm{V}}_{\mathbf{I}_{50}}\right)$ ratios were calculated. TLC, VC, $\mathrm{FEV}_{1}, \mathrm{FEF}_{25-75}$, and RV/ TLC ratio were standardised to permit comparisons between subjects of different age, sex, and height on the basis of the regression equations derived from two large studies of normal values in children and adults. ${ }^{12-14}$ The standardised score or $\mathrm{Z}$ score is the difference between the observed value and the predicted value divided by the residual standard deviation of the variable. This derived standardised score is a measure of the deviation from the expected population mean, age and height being taken into account. The score is on a scale with zero as the mean and unit standard

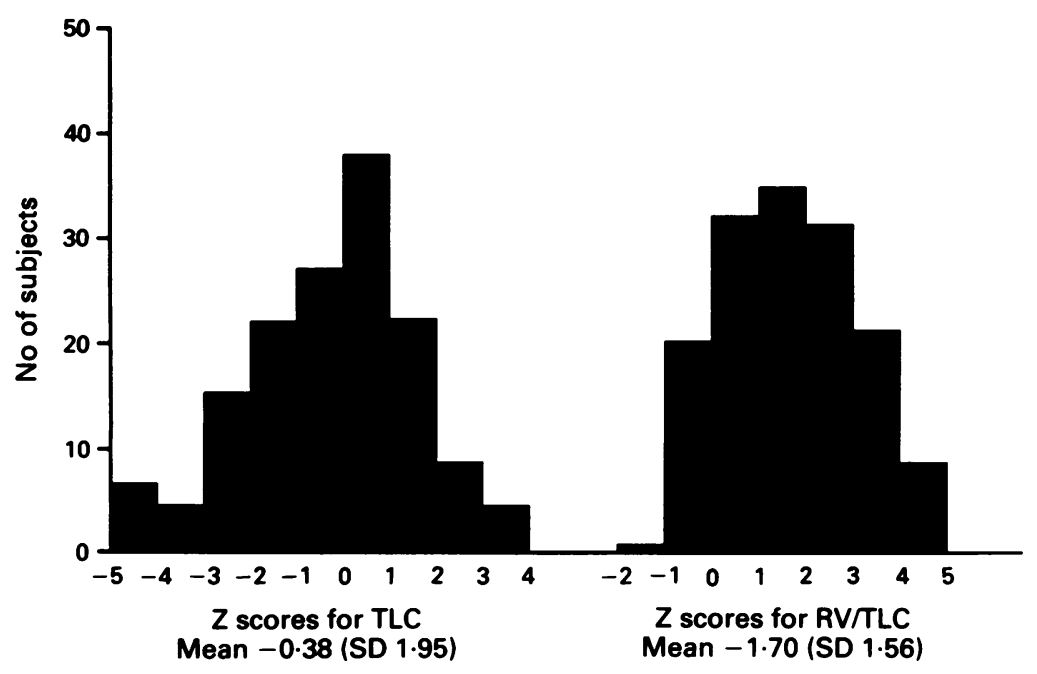

Figure 2 Distribution of total lung capacity (TLC) and residual volume ( $R V) / T L C$ expressed as standardised scores ( $Z$ scores), with the mean and 1 standard deviation of the standardised scores.
Table 1 Sex and age distribution of the 155 patients

\begin{tabular}{rlll}
\hline & \multicolumn{3}{l}{ Number } \\
\cline { 2 - 4 } Age & Total & Male & Female \\
\hline $6-12$ & 36 & 17 & 19 \\
$12-18$ & 45 & 27 & 18 \\
$18-24$ & 41 & 24 & 17 \\
$24-30$ & 23 & 15 & 8 \\
$30-37$ & 10 & 8 & 2 \\
\hline
\end{tabular}

deviation, so that about $95 \%$ of the normal population will have a score ranging from -2 to 2. The normal range for PEF/PIF was 1-1.4 and for $\dot{\mathrm{V}} \mathrm{E}_{50} / \dot{\mathrm{VI}}_{50} 0 \cdot 6-1$ on the basis of published data. ${ }^{15}$

Subjects with an $\mathrm{FEV}_{1} / \mathrm{VC}$ of less than $75 \%$ inhaled $5 \mathrm{mg}$ of nebulised salbutamol and an expiratory flow-volume loop was obtained 10 minutes after they had inhaled bronchodilator. An increase in $\mathrm{FEV}_{1} \%$ predicted of more than $10 \%$ was taken as a positive response.

\section{ANALYSIS}

Student's unpaired $t$ test was used for comparison of lung function data and the $\chi^{2}$ test for analysis of the association between respiratory problems, surgical complications, and gastrointestinal symptoms.

\section{Results}

Lung function studies were carried out on 155 patients with a normal spine. The anatomical abnormalities at presentation were oesophageal atresia and distal fistula in 128, oesophageal atresia and proximal fistula in four, oesophageal atresia alone in nine, and tracheo-oesophageal fistula alone in 14 . The age and sex distribution is shown in table 1.

The distribution of the group in the different ranges of standardised scores for $\mathrm{VC}, \mathrm{FEV}_{1}$, and $\mathrm{FEF}_{25-75}$ is shown in fig 1 . Values less than 2 standardised scores from the expected mean were present in $23(15 \%)$ for VC, $39(25 \%)$ for $\mathrm{FEV}_{1}$, and $22(14 \%)$ for $\mathrm{FEF}_{25-75}$. Five out of 17 patients with an $\mathrm{FEV}_{1} / \mathrm{VC}$ ratio of less than $75 \%$ had a positive response to a $\beta_{2}$ agonist. Figure 2 shows the distribution in the ranges of standardised scores for TLC and RV/TLC. Twenty eight $(18 \%)$ had a TLC value below 2 standardised scores from the mean and 64 $(41 \%)$ an RV/TLC ratio above 2 standardised scores from the mean. The distribution of the different ranges of $\dot{V}_{50} / \dot{V}_{I_{50}}$ and PEF/PIF ratios in the group is shown in fig 3 . Values above the normal range for $\dot{\mathrm{V}} \mathrm{E}_{50} / \dot{\mathrm{VI}}_{50}$ were present in 59 $(38 \%)$ and for PEF/PIF in $76(50 \%)$ of the group. Values below the normal range were present in $16(10 \%)$ and $11(7 \%)$.

Lung function results for patients less than 18 years of age and 18 or more are given in table 2 . It will be noted that the younger patients had a significant reduction in $\mathrm{FEF}_{25-75}$ and a significant increase in the $R V / T L C$ ratio.

In table 3 lung function values are given for the patients divided into groups according to whether they had had admissions for respiratory disease after the initial surgery or radiologically proved gastro-oesophageal reflux in the first five years of life. Patients with respiratory admissions had significantly lower 


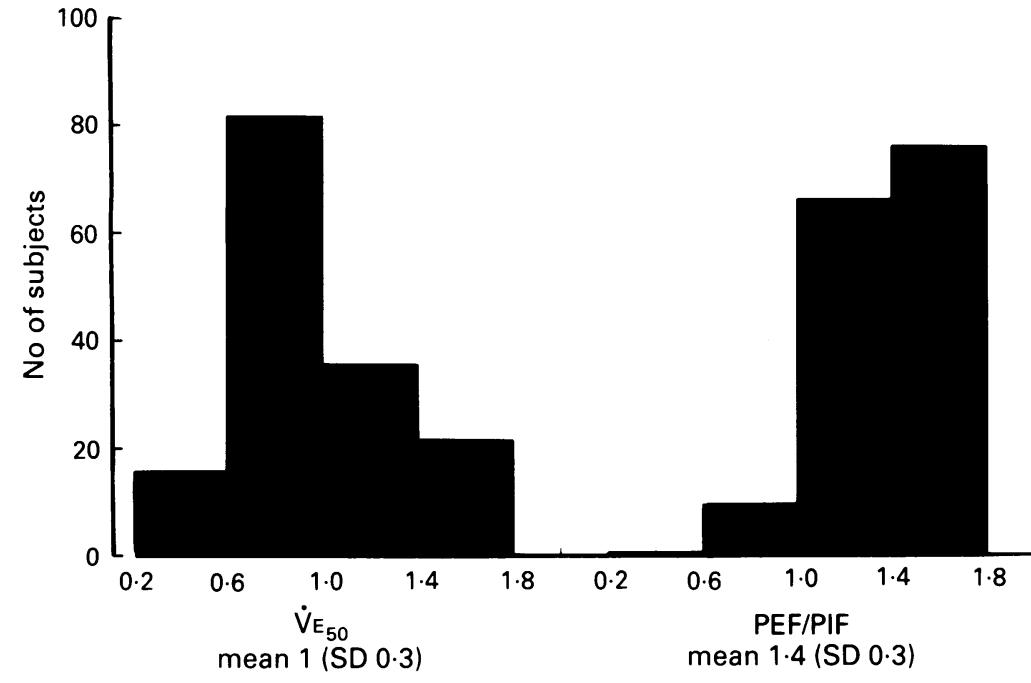

Figure 3 Distribution of mid expiratory to mid inspiratory flow ratio $\left(\dot{V}_{E_{50}} / \dot{V}_{I_{50}}\right)$ and peak inspiratory to peak expiratory flow ratio $(P E F / P I F)$, with mean and 1 standard deviation of the ratios.
Table 2 Lung function data expressed as means (1SD) of the standardised scores for patients less than 18 years of age and 18 years or more

\begin{tabular}{llll}
\hline & $<18$ years & $\geqslant 18$ years & $p$ \\
\hline Number & 81 & 74 & \\
TLC & $-0.54(2.10)$ & $-0.19(1.8)$ & 0.3 \\
VC & $-0.89(1.14)$ & $-0.78(1.24)$ & 0.6 \\
FEV $_{1}$ & $-1.36(1.12)$ & $-1.28(1.11)$ & 0.6 \\
FEF $_{25-75}$ & $-1.17(0.86)$ & $-0.61(0.98)$ & $<0.01$ \\
RV/TLC & $+1.95(1.55)$ & $+1.41(1.53)$ & $<0.05$ \\
\hline
\end{tabular}

TLC-total lung capacity; VC-vital capacity; FEV forced expiratory volume in one second; $\mathrm{FEF}_{25-75}$-forced expiratory volume at $25-75 \%$ of vital capacity.

that lower airways disease was present in as many as $40 \%$ of the group and restrictive lung disease in $18 \%$. In most, however, the abnormalities were relatively minor and under $10 \%$ of patients had evidence of severely deranged function. Airways disease was more pronounced in younger patients. Between a third and a half of our patients had an increase in PEF/PIF and $\dot{V}_{E_{50}} / \dot{V}_{I_{50}}$, suggesting extrathoracic airways obstruction. ${ }^{15-17}$

Previous studies of lung function, which have been on small numbers of patients, have yielded conflicting results. One study showed a prevalence of obstructive airways disease similar to ours but a prevalence of restrictive lung disease of $20 \% .^{7}$ Patients with kyphoscoliosis were included and this may have influenced the findings. Another study, based on only 12 patients, reported mild restrictive lung disease in one third. ${ }^{9}$ A study of 20 patients with troublesome respiratory symptoms found mild restrictive lung disease and extrathoracic airways obstruction. ${ }^{8}$ Finally, mild restrictive lung disease was found in a group with a history of previous pneumonia but not in those who had not had pneumonia. ${ }^{10}$

Several factors possibly contributed to the mild lower airways disease. It may have been secondary to permanent bronchiolar damage from repeated inhalation of gastric and oesophageal contents in the first few years after operation or to increased bronchial hyperreactivity from continuing inhalation. Abnormalities of oesophageal peristalsis predisposing to inhalation are universal after surgical repair, ${ }^{1819}$ and congenital abnormalities of innervation of the oesophageal wall ${ }^{20}$ may compound the problem. Gastro-oesophageal reflux, common after initial surgery, ${ }^{21} 22$ may also contribute to respiratory problems from inhalation and possibly from vagally mediated bron-

Table 3 Lung function data expressed as means (1 SD) of the standardised scores in groups according to whether they had been admitted to hospital for respiratory disease after initial surgery or had gastro-oesophageal reflux $\star$

\begin{tabular}{|c|c|c|c|c|c|c|}
\hline$n:$ & $\begin{array}{l}\text { Respiratory } \\
\text { admissions } \\
65\end{array}$ & $\begin{array}{l}\text { No } \\
\text { admissions } \\
90\end{array}$ & $p$ & $\begin{array}{l}\text { Gastrooesophageal } \\
\text { reflux } \\
76\end{array}$ & $\begin{array}{l}\text { No } \\
\text { reflux } \\
79\end{array}$ & $p$ \\
\hline $\begin{array}{l}\text { TLC } \\
\text { VC } \\
\text { FEV } \\
\text { FEF } \\
\text { RV/TL-75 }\end{array}$ & $\begin{array}{l}-0.59(1.96) \\
-0.92(1.23) \\
-1.59(1.16) \\
-1.15(0.95) \\
+1.83(1.76)\end{array}$ & $\begin{array}{l}-0.21(1.95) \\
-0.78(1.15) \\
-1.20(1.07) \\
-0.80(0.95) \\
+1.59(1.40)\end{array}$ & $\begin{aligned} & 0.4 \\
& 0.5 \\
< & 0.05 \\
< & 0.05 \\
& 0.4\end{aligned}$ & $\begin{array}{l}-0.73(2.12) \\
-0.99(1.14) \\
-1.51(1.14) \\
-1.06(0.93) \\
+1.76(1.65)\end{array}$ & $\begin{array}{l}-0.12(1.71) \\
-0.73(1.21) \\
-1.15(1.04) \\
-0.75(0.95) \\
+1.61(1.52)\end{array}$ & $\begin{aligned} & 0.05 \\
& 0.2 \\
< & 0.05 \\
< & 0.05 \\
& 0.6\end{aligned}$ \\
\hline
\end{tabular}

^Forty one patients were common to the group with respiratory admissions and the group with oesophageal reflux. Abbreviations as in table 2 . 
Table 4 Lung function data expressed as means (1SD) of the standardised scores according to presence and absence of current respiratory and current gastrointestinal symptoms

\begin{tabular}{|c|c|c|c|c|c|c|}
\hline$n:$ & $\begin{array}{l}\text { Current } \\
\text { respiratory } \\
\text { symptoms } \\
83\end{array}$ & $\begin{array}{l}\text { No current } \\
\text { symptoms } \\
72\end{array}$ & $p$ & $\begin{array}{l}\text { Current } \\
\text { gastrointestinal } \\
\text { symptoms } \\
121\end{array}$ & $\begin{array}{l}\text { No current } \\
\text { symptoms } \\
34\end{array}$ & $p$ \\
\hline $\begin{array}{l}\text { TLC } \\
\text { VC } \\
\text { FEV }_{1} \\
\text { FEF }_{25-75} \\
\text { RV/TLC }\end{array}$ & $\begin{array}{l}-0.49(1.97) \\
-0.94(1.25) \\
-1.49(1.17) \\
-1.08(0.96) \\
+1.84(1.57)\end{array}$ & $\begin{array}{l}-0.26(1.95) \\
-0.73(1.11) \\
-1.13(1.03) \\
-0.71(0.91) \\
+1.51(1.54)\end{array}$ & $\begin{array}{c}0.5 \\
0.3 \\
<0.05 \\
<0.01 \\
0.2\end{array}$ & $\begin{array}{l}-0.33(2.01) \\
-0.85(1.24) \\
-1.32(1.18) \\
-0.85(0.97) \\
+1.72(1.62)\end{array}$ & $\begin{array}{l}-0.54(1.76) \\
-0.81(0.97) \\
-1.31(0.86) \\
-1.11(0.86) \\
+1.58(1.32)\end{array}$ & $\begin{array}{l}0.6 \\
0.9 \\
0.9 \\
0.2 \\
0.6\end{array}$ \\
\hline
\end{tabular}

Abbreviations as in table 2 .

choconstriction in the absence of inhalation. ${ }^{2324}$ Variable narrowing of the intrathoracic trachea from tracheomalacia, ${ }^{4525}$ congenital abnormalities of denervation of the trachea, ${ }^{26}$ and bronchomalacia may further distort the expiratory flow-volume loop.

There are several possible reasons why airways dysfunction may have been more pronounced in younger patients. Respiratory problems following repair of oesophageal atresia progressively diminish with growth ${ }^{1}$ and are infrequent in adults. ${ }^{27}$ The advent of neonatal intensive care and mechanical ventilation in the early 1970 s led to the survival of patients with more severe respiratory disease who formerly would have died. ${ }^{28}$ The surgical approach is unlikely to have contributed to the lung function differences as posterolateral thoracotomy through the 4 th or 5 th rib bed has been used since 1950 . Only since the late 1970 s has an intercostal approach been more popular, and most of these patients were too young to perform lung function tests.

Mild restrictive lung disease was seen in a few patients. If the site of the inhaled material was predominantly the alveoli, then recurrent pneumonia may have led eventually to lung fibrosis, with a small loss of lung volume. Retention of secretions from squamous metaplasia of the tracheal mucosa $a^{5}$ and an ineffectual cough from tracheomalacia may have contributed to recurrent pneumonia. Pleural scarring from empyema after anastomotic rupture, an uncommon postoperative complication, and multiple thoracotomies ${ }^{29}$ may also lead to mild restrictive lung disease.

The increase in expiratory flow relative to inspiratory flow suggests extrathoracic tracheal obstruction. Although the rate of inspiratory flow is very effort dependent, great attention was paid in this study to the achievement of maximal efforts by the patients, who were very cooperative. The reduced inspiratory flow therefore is probably genuine; it would be consistent with the presence of tracheomalacia in some patients who died. ${ }^{4}$ The characteristic harsh cough thought to be a manifestation of tracheomalacia did not identify those patients with reduced inspiratory flow.

We documented an increase in lower airways obstruction and a reduction in lung volumes in patients with radiological gastro-oesophageal reflux in the early years after operation. Patients with current gastrointestinal symptoms had lung function similar to that of symptom free subjects, and only a few patients given a bronchodilator had an appreciable response. These findings support the possibility that the lung function abnormalities may be secondary to permanent lung damage from recurrent inhalation in the early years. We cannot exclude the possibility, however, that aspiration occurs without causing symptoms.

This study has documented mild lung function abnormalities in patients aged from 6 to 38 who had oesophageal atresia or tracheooesophageal fistula, or both, repaired in the newborn period. The disorders suggested mainly mild airways obstruction, which seems likely to have been a long term complication of inhalation; this could also explain the restrictive defects found in a few patients. These findings emphasise the importance of early diagnosis and appropriate management of inhalation, particularly gastro-oesophageal reflux, after surgery. Nevertheless, these abnormalities in upper and lower airways function seem to have little impact on the patients and almost all are enjoying a normal lifestyle. ${ }^{27}$ Those who are smoking do not at this stage have significantly worse lung function. As the patients age, however, it will be important to follow them in case they have progressive disease.

1 Dudley NE, Phelan PD. Respiratory complications in long term survivors of oesophageal atesia. Arch Dis Child 1976;51:279-82.

2 Crispin AR, Friedland GW, Waterston DJW. Aspiration pneumonia and dysphagia after technically successful repair of oesophageal atresia. Thorax 1966;21:104-10.

3 Shermata DW, Whitington PF, Seto DS, Haller JA. Lower esophageal sphincter dysfunction in esophageal atresia: nocturnal regurgitation and aspiration pneumonia. $j$ Pediatr Surg 1977;12:871-6.

4 Wailoo MP, Emery JL. The trachea in children with tracheo-oesophageal fistula. Histopathology 1979;3: 329-38.

5 Benjamin B, Cohen D, Glasson M. Tracheomalacia in association with congenital tracheo-oesophageal fistula. Surgery 1976;79:504-8.

6 Emery JL, Haddadin AJ. Squamous epithelium in the respiratory tract of children with tracheo-oesophageal fistula. Arch Dis Child 1971;41:236-42.

7 Milligan DW, Levison $\mathrm{H}$. Lung function in children following repair of tracheo-oesophageal fistula. $J$ Pediatr 1979;95:24-7.

8 Couriel JM, Hibbert M, Olinsky A, Phelan PD. Long-term pulmonary consequences of esophageal atresia with tracheo-oesophageal fistula. Acta Pediatr Scand 1982;71: 973-8.

9 Biller JA, Allen JL, Schuster SR, Treves ST, Winter HS Long term evaluation of esophageal and pulmonary function in patients with repaired esophageal atesia and tracheo-csophageal fistula. Dig Dis Sciences 1987;32 985-90.

10 Le Souef PN, Myers N, Landau LI. Etiological factors in long-term respiratory function abnormalities following 
esophageal atresia repair. J Pediatr Surg 1987;22:918-22.

11 Chetcuti P, Dickens DRV, Phelan PD. Spinal deformity in patients born with oesophageal atresia and tracheo-oesopatients born with oesophageal atresia and trach

12 Zapletal A, Paul T, Samanec M. Die Bedeutung leutiger methoden der lungen funklion zur feststelling einer obstruktion der atemarege bei kinder und Jugendhiken. $Z$ Erkr Atmungsorgine 1977;149:343-71.

13 Knudson RJ, Slatin RL, Lebowitz MD. The maximal expiratory flow volume curve. Normal standards,
variability and effects of age. Am Rev Respir Dis 1976;113:587-600.

14 Knudson RJ, Lebowitz MD, Holberg CJ, Burrows B. Changes in the normal maximal expiratory flow volume curves with growth and ageing. Am Rev Respir Dis 1982;127:725-34

15 Jordanoglou J, Pride NB. A comparison of maximum inspiratory and expiratory flow in health and in lung disease. Thorax 1968;23:38-45.

16 Miller RD, Hyatt RE. Evaluation of obstructing lesions of the trachea by flow volume loops. Am Rev Respir Dis 1973;108:475-81.

17 Kryger M, Bode F, Antri R, Anthonisen N. Diagnosis of obstruction of the upper and central airways. JAMA 1976;61:85-93.

18 Laks H, Wilkinson RH, Schuster SR. Long-term results following correction of esophageal atresia with tracheoesophageal fistula: a clinical and cinefluorographic study. $J$ Pediatr Surg 1972;7:591-7.

19 Romeo G, Zuccarello B, Proietto F, Romeo C. Disorders of the esophageal motor activity in atresia of the esophagus. $J$ Pediatr Surg 1987;22:120-4.

20 Nakazato Y, Landing BH, Wells TR. Abnormal Auerbach plexus in the esophagus and stomach of patients with esophageal atresia and tracheo-esophageal fistula. JPediatr Surg 1986;21:831-7.

21 Whitington PF, Shermeta DW, Seto DSY, Jones C, Hendrix TR. Role of lower esophageal sphincter incompetence in recurrent pneumonia after repair of esophageal atresia. J Pediatr 1977;91:550-4.

22 Parker AG, Christie DL, Cahill JL. Incidence and significance of gastro-oesophageal reflux following repair of esophageal atresia and tracheo-esophageal fistula and the need for antireflux procedures. JPediatr Surg 1979;14:5-8.

23 Danus O, Casar C, Lauvain A, Pope CE. Esophageal refluxan unrecognised cause of recurrent obstructive bronchitis in children. $J$ Pediatr 1976;89:220-4.

24 Mansfield LE, Stein MR. Gastro-esophageal reflux and asthma: a possible reflux mechanism. Ann Allergy 1978;41:224-6.

25 David MRQ, Cywes S. The flaccid trachea and tracheoesophageal congenital anomalies. J Pediatr Surg 978;13:363-7.

26 Nakazato Y, Wells TR, Landing BH. Abnormal tracheal $\vec{\circ}$ innervation in patients with esophageal atresia and tracheo-esophageal fistula: study of the intrinsic tracheal nerve plexuses by a microdissection technique. $J$ Pediatr Surg 1986;21:838-44.

27 Chetcuti P, Myers NA, Phelan PD, Beasley SW. Adults who survived repair of congenital oesophageal atresia and tracheo-oesophageal fistula. BMJ 1988;297:344-6.

28 Myers NA. Oesophageal atresia with distal tracheofistulalong term follow-up. Progr in Pediatr Surg 1977;10:5-17.

29 Chetcuti P, Myers NA, Phelan PD, Beasley SW, Dickens DRV. Chest wall deformity in patients with repaired esophageal atresia. J Pediatr Surg 1989;24:244-7. 